\title{
Standardization and Quality Evaluation of Osmotically Dried Whole Strawberries
}

\author{
Julie Dogra Bandral*, Monika Sood Neeraj Gupta and Jagmohan Singh
}

Department of Food Science and Technology, SK University of Agricultural Sciences and Technology, FoA, Chatha, Jammu \& Kashmir -180009, India

*Corresponding author

\begin{tabular}{|l|}
\hline Ke y w o r d s \\
Osmotic drying, \\
$\begin{array}{l}\text { Honey, Sugar, Shelf } \\
\text { life, Sensory } \\
\text { characteristics }\end{array}$ \\
\hline Article Info \\
\hline $\begin{array}{l}\text { Accepted: } \\
17 \text { October } 2019 \\
\text { Available Online: } \\
\text { 10 November } 2019\end{array}$ \\
\hline
\end{tabular}

\section{A B S T R A C T}

Strawberry (Fragaria $x$ ananassa Duch.) is an edible red fruit which is attractive, luscious, tasty and nutritious with a distinct pleasant aroma and delicate flavour. Strawberries have a short postharvest life due to sensitivity to physiological disorders and infection through several pathogens during transport, storage and processing. In order to enhance the shelf life of strawberries, whole ripe strawberries were treated with osmotic agents viz. sugar and honey (50, 60 and 70\%) for the preparation of strawberry candy followed by packing in polypropylene bags and storage in ambient conditions for shelf life studies. On the basis of the evaluation of range of quality parameters, it was observed that osmotic drying of whole strawberries is possible with different concentration of sugar and honey and retained fresh like characteristics up to 3 months of storage under ambient condition in polypropylene bags. Osmotic drying enhanced the acidity of freshly dried whole strawberries from 0.36 to 0.42 per cent as citric acid and sugar content from 13.21 to 66.38 ${ }^{\circ}$ Brix. Better retention of ascorbic acid $(62.40 \mathrm{mg} / 100 \mathrm{~g})$ and anthocyanin contents $(229.66$ $\mathrm{mg} / 100 \mathrm{~g}$ ) was observed after dipping and drying with sugar solution as compared to control samples having 32.41 and $89.38 \mathrm{mg} / 100 \mathrm{~g}$ ascorbic acid and anthocyanin content. The overall acceptability scores (sensory scores) were higher after osmotic drying of strawberries when compared to control sample (strawberries dried without any osmotic agent). Osmotically drying of strawberries is an effective treatment for extending shelf life of strawberries for three months with better retention of nutritional and sensory characteristics.

\section{Introduction}

Strawberry (Fragaria ananassa) is one of the important fruit belonging to family Rosaceae and is nutritionally rich source of vitamin $\mathrm{C}$, organic acids, anthocyanin, phosphorus, iron, flavonoids, malic acid and other minerals
(Sabina, 2011). The fruit is widely appreciated for its typical aroma, bright red fruit color and juicy texture. Nutritionally, strawberry contains low calorie carbohydrate and a potential source of vitamin $\mathrm{C}$ than oranges. The main composition per $100 \mathrm{~g}$ of fresh strawberries are $91.75 \mathrm{~g}$ water, $7.02 \mathrm{~g}$ 
carbohydrate, $2.3 \mathrm{~g}$ fiber, $14.0 \mathrm{mg}$ calcium, $166.0 \mathrm{mg}$ potassium and $64.4 \mathrm{mg}$ vitamin $\mathrm{C}$ with 27 IU of vitamin A (Dilip, 2016). Strawberries are rich source of diverse range of phytochemicals especially anthocynin, ellagic acid, catechin, quercetin and kemferol alongwith vitamins, fibre and folic acid, that can contribute towards maintenance of good health (Battino et al., 2009; Astawan, 2009). Once harvested strawberries are extremely perishable and have precision postharvest handling requirement. The reason behind their short postharvest is susceptibility towards mechanical injury, physiological deterioration and decay. With the beginning of loss of membrane integrity, the loss of the fruit quality starts leading to senescence ( $\mathrm{Vu}$ et al., 2001).

The berries are consumed in large quantities, either as fresh or in processed foods like preserves, juices, bakery products, ice creams and shakes. It is also used for the production of purees, juice concentrate, jams and red wine alone or in combination with other fruits (Mehriz et al., 2013). The fruits are attractive, luscious, tasty and nutritious with a distinct and pleasant aroma and delicate flavour. But the disadvantage is that the attractive red colour of strawberry juice is highly degraded due to heat processing (Rodrigo and Hendrickx, 2007). Seasonality is one of the key factors which determine the need for fruit processing primarily for juices, beverages and concentrates, but also for solids and frozen or dried products (Sunjka et al., 2004). Short shelf life of strawberries resulted in various technological processes, mainly freezing and processing into jams or beverages for enhancing its utilization. Drying is one of the most important methods that enhance the possibility of extending the shelf life of strawberries and also manufacturing a wide range of new products. In addition, pretreatment processes such as osmotic dehydration with various solutions are used to ensure the desired nutritional and sensory properties of dried products (Kowalska et al., 2017). The most commonly used osmotic substances are sugar and honey. The functionality of fruits can be improved by using an osmotic process to enrich them with functional ingredients. Because of the higher osmotic pressure of the infusion medium, dehydration as well as osmotic exchange of dissolved sugars and ingredients takes place, resulting in the infusion of solids into fruit. Partially dehydrated fruits prepared in this way can be added to food products such as desserts, yogurt, ice-cream and baked goods (Azizah, 2013). In addition, with further drying the infused fruits can be used in dry cereals and snacks. The aim of this study was to analyze sugar and honey as an osmotic substance to enhance bioactive properties of dried strawberries that is rich in nutrients for consumption and utilization for the preparation of various new products.

\section{Materials and Methods}

Fully ripe, even sized bright red coloured strawberries were purchased from the local market. The bruised and diseased fruits were sorted out and only healthy and uniform sized fruits were selected for the study. The stalks were removed with the help of knife. The selected whole fruits were washed by treating with chlorine solution (200 ppm) for 10 minutes and were then air dried for further use. The air dried whole strawberry fruits were divided into seven lots (400g each). Out of these, six lots were immersed in three different concentrations of sugar solution $(50,60$ and $70^{\circ}$ Brix) and honey (50, 60 and $70^{\circ}$ Brix) with Sodium benzoate as chemical preservative. After three days, the strawberries were removed from the solution and excess of sugar and honey syrup was removed followed by freeze drying. One lot (control) was directly freeze dried. Freeze dried whole strawberries were packed in polypropylene bags and kept 
at ambient room temperature for analysis and shelf life studies. The observations for various physico-chemical parameters were recorded at an interval of 30 days. The recorded data were subjected to statistical analysis by adopting factorial CRD.

\section{Chemical characteristics}

The total soluble solids (TSS) of the fruit juice were determined using a hand refractometer and expressed as per cent TSS after making the temperature correction at $20^{\circ} \mathrm{C}$. AOAC (2004) method was used to determine the moisture content of osmotically dries strawberries. The titratable acidity was estimated as per standard procedures by treating against sodium hydroxide solution (Ranganna, 2008). Ascorbic acid content was determined by the procedure of Sadasivam and Manicham (2008) using 2, 6dichlorophenol indophenol dye. Anthocyanin estimation was made as per the procedure cited in hand book of analysis and quality control7. Five ml of nutraceuticals prepared from juice sample was taken in $100 \mathrm{ml}$ conical flask and $50 \mathrm{ml}$ of $0.1 \mathrm{~N} \mathrm{HCl}$ was added. It was shaken well for 10 minutes in mechanical shaker and kept in dark place for one hour. The absorbance was measured at $510 \mathrm{~nm}$ against blank. A standard curve was plotted on graph showing absorbance against the standard (Ranganna, 2008). The overall organoleptic rating of the fruits was done by a panel of ten judges on the basis of colour, flavour (taste + aroma), texture and overall quality rating was calculated making use of a nine point Hedonic scale (Amerine et al., 1965). The data were analyzed statistically in completely randomized design.

\section{Results and Discussion}

Table 1 presents the moisture per cent and titratable acidity per cent of osmotically dried strawberries. The moisture per cent increased with the increasing level of sugar and honey and the values were 12.100, 13.840 and 14.230 per cent in control, in osmotically dried strawberries containing 70 per cent sugar and strawberries dried with 70 percent honey. However, during storage the mean moisture content increased from 14.347 to 16.241 per cent in polypropylene bags, which might be due to absorption of small quantities of moisture by the stored products. Gawale (2014) also reported an increasing trend in moisture content of pineapple-papaya blended leather during 3 months of storage period. Similar trend of increase in moisture during storage has been recorded by Khadtar (2011) in jackfruit bar and Sadawarte (2014) in jamun leather. Titratable acidity on the other hand increased with increase in the level of sugar and honey. The lowest acidity of 0.36 per cent was found in strawberries dried without any osmotic agent but addition of sugar and honey at 60 per cent level resulted in osmotic dried strawberries with 0.39 and 0.40 per cent acidity. The results are in agreement with the conclusions of Ali et al., (1999) who observed an increase in titratable acidity during preservation of persimmon slice. Similar results were investigated by Kumar et al., (2008) in osmotically vacuumed dried mango slice and Khan et al., (2014) in osmotically dried strawberries. The increase in acidity might be due to development of acidic substances by the degradation of pectic bodies or breakdown or oxidation of reducing sugar into acid due to high temperature.

The data in Table 2 reveals that the ascorbic acid content of the leather showed increasing trend with the increasing level of osmotic agents. The combined mean of ascorbic acid increased from $23.24 \mathrm{mg} / 100 \mathrm{~g}$ in $\mathrm{T}_{1}$ (control) to $53.95 \mathrm{mg} / 100 \mathrm{~g}$ in $\mathrm{T}_{3}\left(60^{\circ}\right.$ Brix sugar $)$ and $46.11 \mathrm{mg} / 100 \mathrm{~g}$ in $\mathrm{T}_{6}\left(60^{\circ} \mathrm{Brix}\right.$ honey $)$. Significantly higher vitamin $\mathrm{C}$ content was determined by Kowalska et al., (2018) in dried strawberries previously subjected to osmotic 
dehydration than in those with no pretreatment. According to Santos and Silva (2008), Heng et al., (1990) and Vial et al., (1991), the protective effect on vitamin $\mathrm{C}$ can be attributed to the use of sugar as osmotic substance. As indicated by Santos and Silva (2008), the mechanism of vitamin C degradation primarily depends on water content. The statistical analysis revealed significant differences in the mean values for ascorbic acid during storage and the values decreased during storage due to oxidation of ascorbic acid to dehydroascorbic acid. The oxidative reactions also results in decreased ascorbic acid content of the product during storage (Dalip, 2016). Similar results were observed by Gawale (2014) in pineapplepapaya blended leather, Khan et al., (2014) in guava bar, Shakoor et al., (2015) in guava bar, Chandane (2015) in aonla-mango blended leather during 3 months of storage at ambient conditions

TSS in finished dried strawberries was affected with the addition of sugar and honey and the maximum mean TSS of $66.38^{\circ} \mathrm{Brix}$ was observed in $\mathrm{T}_{4}\left(70^{\circ} \mathrm{Brix}\right.$ sugar $)$ when prepared fresh. Significant changes were observed in TSS during storage and the mean values decreased from 57.41 to 55.96 during 90 days of storage. The trend of decrease in TSS during storage has also been reported by Parekh et al., (2015) in mango bar fortified with desiccated coconut powder. Gawale (2014) and Venilla (2004) also reported similar decrease in TSS values of guavapapaya fruit bar and pine-apple papaya blended leather, respectively.

The anthocyanin is an important parameter for assessing the acceptability of the product. A perusal of data in Table 3 depicts that at 0 day the anthocyanin content were observed highest $229.66(\mathrm{mg} / 100 \mathrm{~g})$ in treatment $\mathrm{T}_{3}\left(60^{\circ}\right.$ Brix sugar). During storage, the mean anthocyanin content decreased from 178.97 to 130.83 $\mathrm{mg} / 100 \mathrm{~g}$. The lowest mean anthocyanin content of $73.99 \mathrm{mg} / 100 \mathrm{~g}$ was observed in $\mathrm{T}_{1}$ (control) followed by $\mathrm{T}_{7}\left(70^{\circ} \mathrm{Brix}\right.$ honey) having anthocyanin content of $131.95 \mathrm{mg} / 100 \mathrm{~g}$. The treatment storage interaction was observed to be significant.

Loss of anthocyanin in osmo dried strawberries might be due to their high susceptibility to auto-oxidative degradation and due to heat degradation during storage (Sherzad et al., 2017). More retention of this characteristic in the product might be due to slower rate of auto oxidation of anthocyanin in the refrigerated storage condition, than ambient condition (Thakur et al., 2013 and Gemenez et al., 2001). Perusal of data further indicates that sensory score for overall acceptability was highest $(8.50)$ in $\mathrm{T}_{3}\left(60^{\circ} \mathrm{Brix}\right.$ sugar) followed by 8.20 in $\mathrm{T}_{4}\left(70^{\circ}\right.$ Brix sugar). However, the lowest mean overall acceptability of 7.15 was obtained in $T_{1}$ (Control). Treatment $\mathrm{T}_{3}\left(60^{\circ}\right.$ Brix sugar) was rated best organoleptically, which might be due to better sugar acid blend of the product. These results are in commerce with Sabrina et al., (2009) who observed decline in the overall acceptability of osmo dehydrated mango slices with inverted sugar syrups and with sucrose syrup Sabina et al., (2011). Gamboa-Santos et al., (2014) performed sensory evaluation of dried and rehydrated strawberries reported higher flavor and texture values for the freeze dried fruit compared to the convectionmicrowave-vacuum dried samples.

It can be concluded from the study that the osmo dried strawberries prepared after dipping in $60^{\circ}$ Brix sugar followed by freeze drying had the best organoleptic quality. The mean values of TSS, anthocyanin and ascorbic acid increased significantly with the increase in sugar content. Therefore, best quality osmo dried strawberries can be prepared by using sugar syrup of concentration $60^{\circ}$ Brix having shelf life of 3 months 
Table.1 Effect of osmotic agents on Moisture content and Titratable acidity of osmotically dried whole strawberries

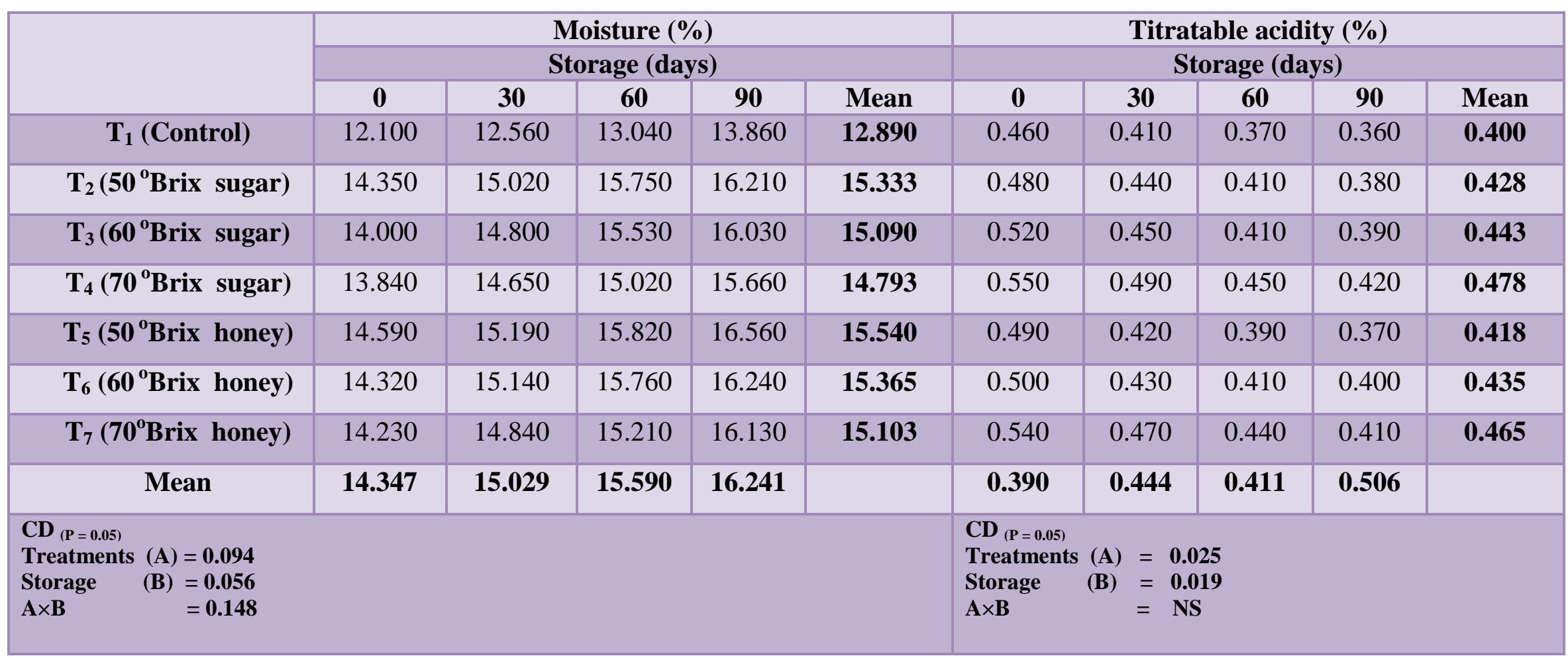


Table.2 Effect of osmotic agents on TSS and Ascorbic acid content of osmotically dried whole strawberries

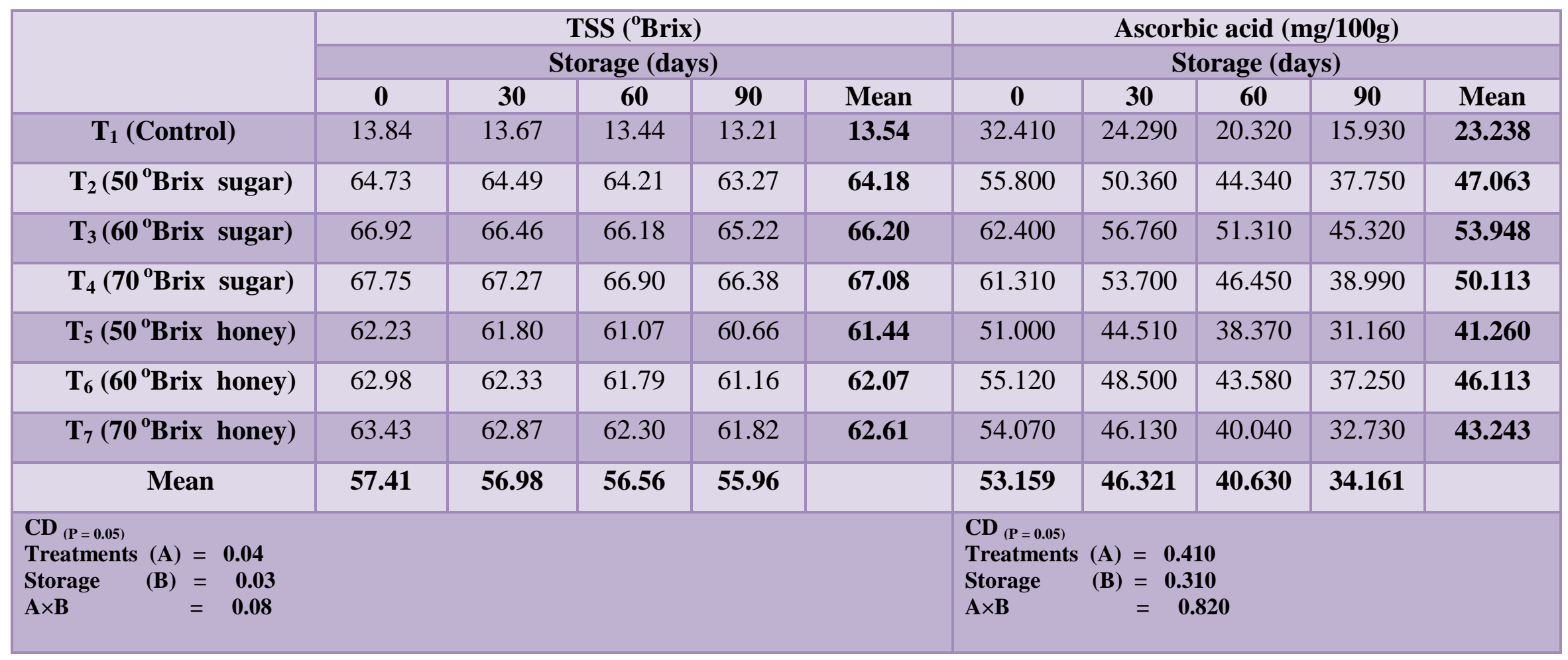


Table.3 Effect of osmotic agents on anthocyanin and overall acceptability scores of osmotically dried whole strawberries

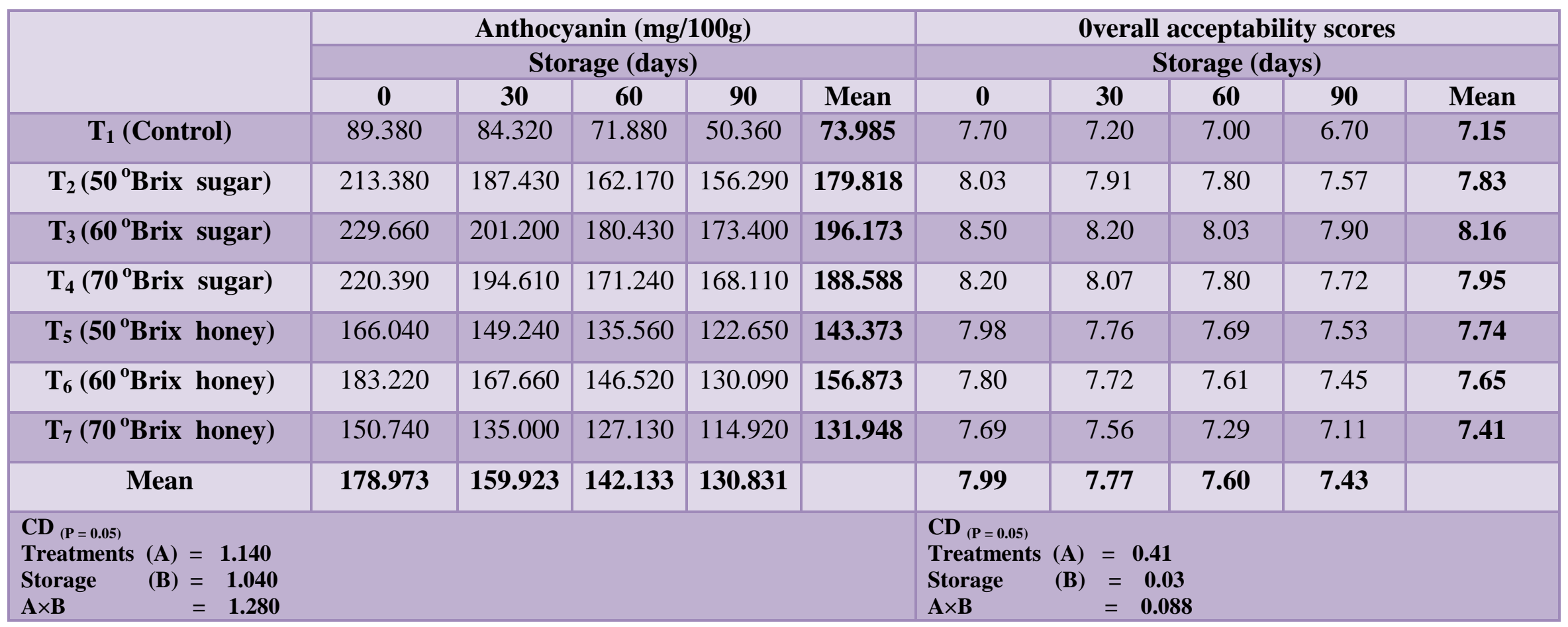




\section{References}

Ali. A., Abrar, M., Sultan, M.T., Din, A. and Niaz, B. 1999. Postharvest physicochemical changes in full ripe strawberries during cold storage. Animal and Plant Science 21: 38-41.

Amerine, M.A., Pangborn, R.M. and Rosseler, E.B. 1965. Principles of Sensory Evaluation of Foods, Academic Press. New York. pp. 350-376.

AOAC. 2004. Official Methods of Analysis. Association of Official Analytical Chemists. Washington D.C, USA.

Astawan, M. 2009. Study of Phyto chemical compounds in strawberry, Encyclopedia Pakistan Journal of Nutrition, Jakarta.

Azizah, M. 2013. Evaluation of Post Harvest Technologies for Improving Strawberry Fruit Quality. The University of Guelph. Ontario, Canada

Battino, M., Beekwilder, J., Denoyes-Rothan, B., Laimer, M., McDougall, G.J. and Mezzetti, B. 2009. Bioactive compounds in berries relevant to human health. Nutrition Reviews, 67, S145-S150.

Burda, S. and Oleszek, W. 2001. Antioxidant and antiradical activities of flavonoids. Journal of Agricultural and Food Chemistry, 49: 2774-2779.

Chandane, N. S. 2014. Studies on preparation of blended aonla - mango leather, Thesis submitted to Post Graduation Institute of Post Harvest Management, Killa-Roha.

Dilip, D.M. 2016. Studies on preparation of strawberry (fragaria $x$ ananassa duch.) fruit leather. M.Sc. Dissertation submitted to Dr. Balasaheb Sawant Konkan Krishi Vidyapeeth, Dapoli Ratnagiri (India)

Gamboa-Santos, J., Meg1 'as-Pe 'rez R, Cristina, S. A., Olano, A., Montilla, A.and Villamiel, M. 2014. Impact of processing conditions on the kinetic of vitamin $\mathrm{C}$ degradation and 2furoylmethyl amino acid formation in dried strawberries. Food Chemistry, 153:164-170

Gawale, N. S. 2014. Studies on preparation of blended pineapple-papaya leather. Thesis submitted to Post Graduation Institute of Post Harvest Management, Killa-Roha.

Gimenez, J., Kajda, P., Margomenou, L., Piggott, J.R. and Zabetakis, I. 2001. A study on the colour and sensory attributes of high hydrostatic-pressure jams as compared with traditional jams. Journal of Science of Food and Agriculture. 81: 1228-1234.

Heng, K., Guilbert, S. and Cuq, J,L. 1990. Osmotic dehydration of papaya: influence of process variables on the product quality. Science Des Aliments. 10: $831-848$

Khadtar, 2011. Studies on standardization of jackfruit (Artocarpus heterophyllus) bar, Thesis submitted to Post Graduate Institute of Post Harvest Management, Killa-Roha.

Khan, A., Shamrez, B., Litaf, U., Zeb, A and Rehman, Z. 2014. Effect of sucrose solution and chemical preservatives on overall quality of strawberry fruit. Journal of Food Process Technology, 6: 41

Kowalska, H., Marzec, A., Kowalska, J., Ciurzyn'ska, A., Czajkowska, K., Cichowska, J., Rybak, K. and Lenart, A. 2017. Osmotic dehydration of Honeoye strawberries in solutions enriched with natural bioactive molecules. LWT Food Science and Technology, 85:500-505

Kowalska, J., Kowalska, H., Agata Marzec, A., Brzezin 'ski1, T., Samborska, K. and Lenart, A. 2018. Dried strawberries as a high nutritional value fruit snack. Food Science and 
Biotechnology, 27(3):799-807

Kumar SP, and Sagar VR (2008) Quality of osmovac dehydrated ripe mango slices influenced by packaging material and storage temperature. Journal of Scientific and Industrial Research, 67: 1108-1114.

Mehriz, A.S.M., Abou, D.A. and Hebeishy, E.H. 2013. Properties and antioxidant activity probiotic yoghurt flavored with black carrot, pumpkin and strawberry. International Journal of Dairy Science, 8(2): 48-57

Parekh J. H., Senapati A. K, Balb L.M., and Pandita P. S. 2015. Quality Evaluation of Mango Bar with Fortified Desiccated Coconut Powder during Storage, Journal of Bioresource Engineering and Technology, 1: 40-47

Ranganna, S. 2008. Manual of analysis of Fruit and Vegetable products, Tata MC Graw Hill Publishing Company Ltd. New Delhi.

Rodrigo, L.V. and Hendrickx. 2007. Combined thermal and high pressure degradation of Tomato puree and strawberry juice, Journal of Food Engineering, 79 (2): 553-560.

Sabina, R., Miyan, S.H. and Hoque, M.M. 2011. Studies on the effects of chemical preservatives on the quality of strawberry (Fragaria ananassa) juice in Bangladesh. International Journal of Natural Sciences, 1(4):97101.

Sabrina, B., Renata, B.B., Bruna, M., Petrus, R.R., and Carmen, E. 2009. Quality and sensorial characteristics of osmotically dehydrated mango with syrups of inverted sugar and sucrose. Scientia Agricola (Piracicaba, Braz) 66: 40-43.

Sadasivam S, Manicham A. Biochemical Methods. New Age International Publisher, New Delhi, 2008, 215-216.

Sadawarte 2014. Studies on preparation of
Jamun (Syzigium cumini L.) leather from jamun pulp, Thesis submitted to Post Graduate Institute of Post Harvest Management, Killa-Roha.

Santos, P.H.S. and Silva, M.A. 2008. Retention of vitamin $\mathrm{C}$ in drying processes of fruits and vegetables - a review. Drying Technology, 26: 14211437.

Shakoor, A., Ayub, M., Wahab, S., Khan, M., Khan, A. and Rahman Z. 2015. Effect of Different Levels of Sucrose-Glucose Mixture on Overall Quality of Guava Bar. Journal of Food Process Technology, 6(8): 2-7.

Sherzad, R.A., Sreenivas, K. N., Sadananda, G. K. H., Ulla, M.T. and Esmail, S. 2017. Standardization of Product Development Protocol of Strawberry (Fragaria ananassa) Based Blended Nectar Beverage and Its Storage. International Journal of Pure and Applied Bioscience, 5(1): 338-348.

Singleton, V.L., Orthofer, R., and LamuelaRaventós, R.M. 1999. Analysis of total phenols and other oxidation substrates and antioxidants by means of Folin ciocalteu reagent. In Methods in enzymology. P. Lester, (ed.) Academic Press, pp. 152-178.

Sunjka, P.S., Rennie, T.J., Beaudry, C. and Raghavan, G.S.V. 2004. Microwave convective and microwave-vacuum drying of cranberries: a comparative study. Drying Technology, 22: 12171231

Thakur, N.S., Girish, S.D. and Joshi V.K. 2013 Development of wild pomegranate aril-insyrup and its quality evaluation during storage. International Journal of Food and Fermentation Technology, 3(1): 33-40

Venilla P. 2004. Studies on storage behaviour of guava-papaya bar. Beverage and Food world. 31(2): 63-66.

Vial, C., Guilbert, S. and Cuq, J.L. 1991. 
Osmotic dehydration of kiwi fruits: influence of process variables on the color and ascorbic acid content. Science Des Aliments. 11: 63-84

Vu, K.D.; Hollingsworth, R.G.; Leroux, E.; Salmieri, S.; Lacroix, M. 2001.
Development of edible bioactive coating based on modified chitosan for increasing the shelf life of strawberries. Food Research International, 44: 198-203.

\section{How to cite this article:}

Julie Dogra Bandral, Monika Sood Neeraj Gupta and Jagmohan Singh. 2019. Standardization and Quality Evaluation of Osmotically Dried Whole Strawberries. Int.J.Curr.Microbiol.App.Sci. 8(11): 2126-2135. doi: https://doi.org/10.20546/ijcmas.2019.811.247 